\title{
DIFFERENT EXPERIMENTAL MODELS USED TO INDUCE DIABETES MELLITUS IN RODENTS: A REVIEW
}

\author{
RESHMI CHAKRABORTY*, ABDUL BAQUEE AHMED, DIPANKAR SAHA \\ Girijananda Chowdhury Institute of Pharmaceutical Sciences, Guwahati, Assam, India 781017 \\ Email: reshmi.c94@gmail.com
}

Received: 18 Apr 2019, Revised and Accepted: 26 Jun 2019

\begin{abstract}
Diabetes is a metabolic disease characterized by the presence of hyperglycemia resulting from either defects in insulin secretion or action or both. Various processes are involved in the development of diabetes. These range from autoimmune destruction of the insulin-producing cells, $\beta$-cells of the pancreas, a dysfunction of the pancreatic $\beta$-cell, and impaired insulin action through insulin resistance. Experimental diabetes in animals are widely induced by administration of alloxan and streptozotocin at a proper dose. The mechanism of their action in pancreatic $\beta$-cells has been extensively investigated. Reactive oxygen species are responsible for the cytotoxic action of both these diabetogenic agents. However, the source of their generation is different in the case of alloxan (ALX) and streptozotocin (STZ). In one of the study, it is also showed that the administration of a high-fat diet (HFD) to rats for $16 \mathrm{w}$ showed a progressive increase in body weight, energy intake, abdominal fat deposition, and abdominal circumference along with impaired glucose tolerance, dyslipidemia and hyperinsulinemia. Administration of alloxan or streptozotocin in addition with HFD is also able to induce diabetes in an experimental rat model.
\end{abstract}

Keywords: Insulin resistance, Alloxan, Streptozotocin, High fat diet

(C) 2019 The Authors. Published by Innovare Academic Sciences Pvt Ltd. This is an open access article under the CC BY license (http://creativecommons.org/licenses/by/4.0/] DOI: http://dx.doi.org/10.22159/ijcpr.2019v11i4.34952

\section{INTRODUCTION}

Diabetes mellitus (DM) is a chronic metabolic disorder that can alter carbohydrate, protein, and fat metabolism. It is caused by the absence of insulin secretion due to $\beta$-Langerhans islet cells destruction of the pancreas to produce insulin caused by an autoimmune process, usually leading to absolute insulin deficiency, or due to defects in insulin uptake in the peripheral tissue known as insulin resistance [1]. DM is broadly classified under two major categories, which include insulin dependent diabetes mellitus (IDDM, type I diabetes) and non-insulin dependent diabetes (NIDDM, type II diabetes) [2] Type I diabetes mellitus (T1DM) is the most prevalent type of diabetes among children and young adults in developing nations, and was formally termed juvenile diabetes. Type I diabetes is thought to result in people whose immune systems are genetically predisposed to develop a vigorous autoimmune response against $\beta$-pancreatic cell antigen, while Type 2 diabetes mellitus (T2DM) results from the failure of the body to respond to insulin, known as insulin resistance, along with the inability to produce enough insulin to overcome this insulin resistant state. This common form of diabetes is often associated with obesity [3].

Animal models have played a great role in the study of diabetes. Such animal models allow the researchers to study the in vivo, genetic, and environmental factors that may influence the development of the disease and its secondary complications, thus gaining useful information for its management and treatment in humans. The first method of experimental diabetes was induced by total or partial pancreatectomy. The second method of producing diabetes was by means of anterior pituitary extract. The third method of experimental diabetes was produced in 1943 by the administration of alloxan after the discovery by Dunn, Sheehan and McLetchie that this substance can cause necrosis of the pancreatic islets of langerhans in rabbits. There are many animal models of diabetes, some may develop the disease spontaneously or in a diet-induced manner, While others may show a genetic predisposition to the disease [4-7]. The rodent models of diabetes are induced by chemicals, biological agents, peptides, potentiators, and steroids but most commonly used chemicals agents are alloxan and streptozotocin in addition to the high fat diet.

Induction of diabetes

\section{Alloxan}

Dunn, Sheehan and McLetchie at the University of Glasgow in 1943 reported that the administration of alloxan can cause necrosis of pancreatic islet in rabbits. In 1937 Jacobs observed that alloxan can exert its effect in blood glucose levels, but had studied only the early hypoglycemia; but did not carry out the study on animals for a sufficient period of time so as to study the development of hyperglycaemia [8-10] Very soon many other findings were confirmed by other investigator and introduced the term "alloxan diabetes" [11-13].

Alloxan is a diabetogenic agent which is used for the induction of experimental diabetes in animals such as rabbits, rats, mice and dogs. It is basically a urea derivative which causes selective necrosis of the pancreatic islets. $[14,15]$ Alloxan can be administered intravenously, parenterally, subcutaneously or intraperitoneally. The alloxan dose usually depends on the animal species, route of administration and nutritional status. Alloxan usually doesn't have a promising effect in human islets as it is more resistant to alloxan than those of the rat and mouse [16]. The intravenous dose of this drug most frequently used to induce diabetes in rats is $65 \mathrm{mg} / \mathrm{kg}$ b.w. [17]. The effective dose of alloxan becomes higher 2-3 times when it is given intraperitoneally or subcutaneously. The intraperitoneal dose should be above $150 \mathrm{mg} / \mathrm{kg}$ b.w. for inducing diabetes in the rat. Usually fasted animals are more susceptible to alloxan [18].

\section{Mechanism of action}

The mechanism of action of alloxan has been studied intensively in vitro, and is now characterized quite well. The diabetogenic action of alloxan in the pancreas is preceded by its rapid uptake by insulinsecreting pancreatic beta cells. After its uptake, the reduction process of alloxan occurs in the presence of different reducing agents like cysteine, ascorbate, reduced glutathione (GSH), and protein-bound sulfhydryl (-SH) groups $[19,20]$. Alloxan has a high affinity to bind with two-SH groups in the sugar binding site of glucokinase resulting in the inactivation of the enzyme. Reduction of alloxan results in the formation of dialuric acid which is then reoxidized back to alloxan. A redox cycle is established which generates reactive oxygen species (ROS) and superoxide radicals. The superoxide radicals are able to liberate ferric ions from ferritin and reduce them to ferrous and ferric ions and they also undergo dismutation to form hydrogen peroxide $\left(\mathrm{H}_{2} \mathrm{O}_{2}\right)$. This leads to the formation of, highly reactive hydroxyl radicals. ROS also has a prominent effect on the DNA of the pancreatic islets. When the beta cells are exposed to alloxan it causes DNA fragmentation and 
damage. In addition disturbances in intracellular calcium homeostasis also has also been reported to play a major role in diabetogenic action of alloxan. Alloxan has the ability to open voltage-dependent calcium channels which results in the influx of calcium into pancreatic cells. The increased concentration of $\mathrm{Ca}^{2+}$ ion results in the supraphysiological release of insulin. The increased concentration of insulin along with ROS eventually leads to the destruction of beta cells of pancreatic islets [21, 22].

Table 1: Composition of HFD

\begin{tabular}{ll}
\hline Ingredients & Diet(g/Kg) \\
\hline Powdered NPD & 365 \\
Lard & 310 \\
Casein & 250 \\
Cholesterol & 10 \\
Vitamin and mineral mix & 60 \\
DL-Methionine & 03 \\
Yeast powder & 01 \\
Sodium chloride & 01 \\
\hline
\end{tabular}

\section{Streptozotocin}

Streptozotocin is a naturally occurring chemical isolated from Streptomyces achromogenes; which used to produce both Type- 1 and Type-2 diabetes mellitus [23].

The dose range of the streptozotocin (STZ) is not as narrow as compared to alloxan (ALX). The most frequently used single intravenous dose is between 40 and $60 \mathrm{mg} / \mathrm{kg} \mathrm{b.w}$. to induce IDDM in adult rats, but higher doses can also be used. A similar or higher dose of STZ can be administered when it is administered intraperitoneally, but single dose below $40 \mathrm{mg} / \mathrm{kg}$ b.w. may not be effective. STZ can also be administered by an intravenous or intraperitoneal route on the day of birth in rats at a dose of $100 \mathrm{mg} / \mathrm{kg}$ b.w. to induce type 2 diabetes. At 8-10 $\mathrm{w}$ of age and thereafter, the rats treated with STZ exhibit mild hyperglycemia $[24,25]$.

\section{Mechanism of action}

Streptozotocin prevents the synthesis of DNA (Deoxyribonucleic acid) in the mammalian cells. STZ reacts with cytosine groups, which results in the degeneration and destruction of DNA. The streptozotocin enters the pancreatic cell via a glucose transporterGLUT2 (Glucose transporter 2) and this leads to alkylation of DNA. Moreover, STZ also induces activation of polyadenosine diphoshate ribosylation and release of nitric oxide. NO has a cytotoxic effect on the pancreatic islet cells, and this leads to the necrosis of the cells which finally lead to diabetes mellitus. Calcium does not play any significant role in the destruction of pancreatic $\beta$ cell induced by STZ, as they do in the case of alloxan [26-28].

\section{High-fat diet and low dose ALX/STZ induced hyperglycemia}

According to the WHO, in 2016 more than 1.9 billion adults were overweight, and among them, 650 million were obese [29]. Increased incidence of obesity results in a higher prevalence of T2DM [30]. Hyperglycemia in rats by administration of STZ or ALX is primarily due to the direct necrosis of the pancreatic beta cell, which results in insulin deficiency rather than the consequence of insulin resistance $[31,32]$. Thus, they depict symptoms of human T1DM rather than T2DM. In contrast, high-fat diet (HFD) fed rats develop obesity, hyperinsulinemia, and insulin resistance and not frank hyperglycemia [33, 34]. Hence, there exists a continued research among the investigators to establish an ideal animal model to study T2DM either by modifying the existing models or by developing some new methodologies or by the combination of both [35].

The HFD was formulated as $58 \%$ fat, $25 \%$ protein and $17 \%$ carbohydrate, as a percentage of total kcal $[35,36]$. The fat plays a major role as it is able to produce insulin resistance syndrome in rats over a short period of time. It leads to increase in body weight (obesity), hyperglycemia, hypertriglyceridemia, hypercholesterolemia [37, 38]. HFD is able to induce insulin resistance mainly through Randle or glucose-fatty acid cycle [39]. Due to excess intake of fat the level of triglyceride increases and this leads to an increased availability of fatty acid and oxidation. The use of increased fatty acids for oxidation leads to an insulin-mediated reduction of hepatic glucose output and reduces the glucose uptake in skeletal muscle leading to hyperinsulinemia, which is a common feature in case of insulin resistance [40-42]. The saturated fat (lard) which gets deposited in various body fat pads which is present in HFD might be responsible for increase in body weight and also decrease in energy expenditure as compared to NPD-fed animals. The composition of HFD is shown in table 1.

Many studies were also carried out to find a suitable dose of STZ that is low enough to ensure the development of T2DM in HFD fed rats. Different doses of STZ $\left(25,35,45\right.$ and $55 \mathrm{mg} \mathrm{kg}^{-1}$, i. p.) were studied. The HFD rat model with low dose of STZ (35 mg kg-1) was considered to be more effective to represent the pathophysiological state of type 2 diabetes and was chosen for further studies. [37] In another study Type 2 diabetes was induced using high-fat diet and low-dose of streptozotocin $(30 \mathrm{mg} / \mathrm{kg})$. In this model, insulin resistance is induced two weeks after HFD, followed by low-dose administration of STZ which caused partial $\beta$-cell dysfunction.

In another study fasted rats were injected with alloxan in a dose of $55 \mathrm{mg} / \mathrm{kg}$. The rats were confirmed hyperglycemic after $72 \mathrm{~h}$ post alloxan administration. Simultaneously, diabetic rats were allowed free access to HFD for the induction of diabetic dyslipidemia [43].

\section{CONCLUSION}

Official reports indicate that throughout the world the incidence of Diabetes mellitus is increasing. To reduce the data, the development of new antidiabetic drugs is important and many research is going on for the development of more effective anti-hyperglycemic drugs. Animal model plays a major role to study the mechanism of drugs that may cause hyperglycemia. In this review, we have given an overview of models used to induce diabetes and their mechanism of action. Conclusively, there are many animal models which are used to induce diabetes, which further help in the study of the development of new anti-diabetic drugs.

\section{ACKNOWLEDGMENT}

Authors would like to thank the Faculties of Girijananda Chowdhury Institute of Pharmaceutical Sciences for providing the necessary support to carry out the study.

\section{CONFLICT OF INTERESTS}

\section{Declare none}

\section{REFERENCES}

1. Baynest HW. Classification, pathophysiology, diagnosis and management of diabetes mellitus. Baynes J Diabetes Metab 2015;6:5.

2. WHO Expert Committee on Definition, Diagnosis and Classification of Diabetes Mellitus and its Complications; 1999. p. 1-59.

3. Jun Y, Shen J, Sun TT, Zhang X, Wong N. Obesity, insulin resistance, NASH and Hepatocellular carcinoma, Seminars in cancer biology; 2013. 
4. Sheehan HL, McLetchie NGB. Necrosis of islets of langerhans produced experimentally. Lancet 1943;1:484-7.

5. Islam MS, DuLoots T. Experimental rodent models of type 2 diabetes: a review. Methods Find Exp Clin Pharmacol 2009;31:249-61.

6. Liu RH, Mizuta M, Kurose T, Matsukura S. Early events involved in the development of insulin resistance in zucker fatty rat. Int J Obes Relat Metab Disord 2002;26:318-26.

7. Dourmashkin JT, Chang GQ, Gayles EC, Hill JO, Fried SK, Julien $\mathrm{C}$, et al. Different forms of obesity as a function of diet composition. Int J Obes (Lond) 2005;29:1368-78.

8. Jacobs HR. Hypoglycemic action of alloxan. Proc Soc Exp Biol Med 1937;37:407-9.

9. Bailey CC, Bailey OT. The production of diabetes mellitus in rabbits with alloxan. J Am Med Assoc 1943;122:1165-6.

10. Brunschwig A, Goldner MG, Allen JG, Gomori G. Alloxan. J Am Med Assoc 1943;122:966.

11. Dunn JS, McLetchie NGB. Experimental alloxan diabetes in the rat. Lancet 1943;2:384-7.

12. Goldncr MG, Gomori G. Alloxan diabetes mellitus in the dog. Endocrinology 1943;33:297-308.

13. Gomori G, Goldner MG. Production of diabetes mellitus in rats with alloxan. Proc Soc Exp Biol Med 1943;54:287-90.

14. Etuk EUNJ. Animals models for studying diabetes mellitus. Agric Biol 2010;1:130-4.

15. Iranloye BO, Arikawe AP, Rotimi G, Sogbade AO. Anti-diabetic and anti-oxidant effects of zingiber officinale on alloxaninduced and insulin-resistant diabetic male rats. Physiol Soc Nigeria 2011;26:89-96.

16. Eizirik dl, Pipeleers Dg, Ling Z, Welsh N, Hellerstrom C, Andersson A. Major species differences between humans and rodents in the susceptibility to pancreatic beta-cell injury. Proc Natl Acad Sci USA 1994;91:9253-6.

17. Gruppuso PA, Boylan JM, Posner BI, Faure R, Brautigan DL. Hepatic protein phosphotyrosine phosphatase. Dephosphorylation of insulin receptor and epidermal growth factor receptors in normal and alloxan diabetic rats. J Clin Invest 1990;85:1754-60.

18. Katsumata K, Katsumata KJr, Katsumata Y. Protective effect of Diltiazem hydrochloride on the occurrence of alloxan-or streptozotocin-induced diabetes in rats. Horm Metab Res 1992;24:508-10.

19. Lenzen S, Munday R. Thiol-group reactivity, hydrophilicity and stability of alloxan, its reduction products and its N-methyl derivatives and a comparison with ninhydrin. Biochem Pharmacol 1991:42:1385-91.

20. Zhang H, Zdolsek JM, Brunk UT. Alloxan cytotoxicity involves lysosomal damage. APMIS1992;100:309-16.

21. Munday R. Dialuric acid autoxidation. Effects of transition metals on the reaction rate and on the generation of "active oxygen" species. Biochem Pharmacol 1988;37:409-13.

22. Das J, Vasan V, Sil PC. Taurine exerts a hypoglycemic effect in alloxan-induced diabetic rats, improves insulin-mediated glucose transport signaling pathway in heart and ameliorates cardiac oxidative stress and apoptosis. Toxicol Appl Pharmacol 2012;258:296-308.

23. Herr RR, Jahnke JK, Argoudelis AD. The structure of streptozotocin. J Am Chem Soc 1967;89:4808-9.

24. Ganda OP, Rossi AA, Like AA. Studies on streptozotocin diabetes. Diabetes 1976;25:595-603.

25. Katsumata K, Katsumata KJr, Katsumata Y. Protective effect of diltiazem hydrochloride on the occurrence of alloxan-or streptozotocin-induced diabetes in rats. Horm Metab Res 1992;24:508-10.

26. Portha B, Levacher C, Picon L, Rosselin G. Diabetogenic effect of streptozotocin in the rat during the perinatal period. Diabetes 1974;23:889-95.

27. Mythili MD, Vyas R, Akila G, Gunasekaran S. Effect of streptozotocin on the ultrastructure of rat pancreatic islets. Microsc Res Tech 2004;63:274-81.

28. Patel R, Shervington A, Pariente JA, Martinez Burgos MA, Salido GM, Adeghate E, et al. Mechanism of exocrine pancreatic insufficiency in streptozotocin-induced type 1 diabetes mellitus. Ann NY Acad Sci 2006;1084:71-88

29. Centro de prensa de la Organización Mundial de la Salud. Obesidad y sobrepeso. Available from: http://www.who.int/ mediacentre/factsheets/fs311/e/. [Last accessed on 16 Jun 2019].

30. Almanza MR, Gomez RC, Torres JFM. Obesity and type 2 diabetes: also linked in therapeutic options. Endocrinol Diabetes Nutr 2019;66:140-9.

31. Shafrir E. Diabetes in animals: contribution to the understanding of diabetes by the study of its etiopathology in animal models. In: Porte D, Sherwin RS, Baron A. editors. Diabetes mellitus. NewYork: McGraw-Hill; 2003. p. 231-55.

32. Rerup CC. Drugs producing diabetes through damage of the insulin-secreting cells. Pharmacol Rev 1970;22:485-518.

33. Storlien LH, James DE, Burleigh KM, Chisholm DJ, Kraegen EW. Fat feeding causes widespread in vivo insulin resistance, decreased energy expenditure and obesity in the rat. Am J Physiol 1986;251:576-83.

34. Srinivasan K, Patole PS, Kaul CL, Ramarao P. Reversal of glucose intolerance by pioglitazone in high-fat diet fed rats. Methods Find Exp Clin Pharmacol 2004;26:327-33.

35. Reed MJ, Meszaros K, Entes LJ, Claypool MD, Pinkett JG, Gadbois TM, et al. A new rat model of type 2 diabetes: the fat-fed, streptozotocin-treated rat. Metabolism 2000;49:1390-4.

36. Reed MJ, Meszaros K, Entes LJ, Claypool MD, Pinkett JG, Gadbois TM, et al. A new rat model of type 2 diabetes: the fat-fed, streptozotocin-treated rat. Metabolism 2000;49:1390-4.

37. K Srinivasan, B Viswanad, L Asrat, CL Kaul, P Ramarao. Combination of high-fat diet-fed and low-dose streptozotocintreated rat: a model for type 2 diabetes and pharmacological screening. Pharmacol Res 2005;52:313-20.

38. Reaven GM. Insulin resistance, hyperinsulinemia hypertriglyceridemia and hypertension: parallels between human disease and rodent models. Diabetes Care 1991;14:195-202.

39. Randle PJ, Garland PB, Hales CN, Newsholme EA. The glucosefatty acid cycle. Its role in insulin sensitivity and metabolic disturbances in diabetes mellitus. Lancet 1963;1:785-9.

40. Belfiore F, Iannello S. Insulin resistance in obesity: metabolic mechanisms and measurement methods. Mol Gen Metab 1998;65:121-8.

41. Iwanishi M, Kobayashi M. Effect of pioglitazone on insulin receptors of skeletal muscles from high-fat-fed rats. Metabolism 1993;42:1017-21.

42. Rosholt MN, King PA, Horton ES. High-fat diet reduces glucose transporter responses to both insulin and exercise. Am J Physiol 1994;266:95-101.

43. Li-Qin Tang, Wei Wei, Li-Ming Chen, Sheng Liu. Effects of berberine on diabetes induced by alloxan and a high-fat/highcholesterol diet in rats. J Ethnopharmacol 2006;108:109-15. 